\title{
Economic SYNOPSES
}

short essays and reports on the economic issues of the day

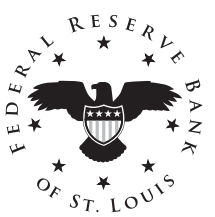

2002 Number 10

\section{The Balance of Risks}

\author{
David C. Wheelock
}

A

$\mathrm{t}$ its March 19, 2002, meeting, the Federal Open Market Committee (FOMC) concluded that for the foreseeable future the risks of economic weakness and of heightened inflation pressures are balanced. This was the first time since February 2000, when the FOMC began to issue statements about such risks, that the Committee issued a statement indicating balance. This meeting was also the second consecutive meeting at which the FOMC did not change its federal funds rate target despite the fact that the Committee statement from its immediately prior meeting had indicated that "the risks are weighted mainly toward conditions that may generate economic weakness in the foreseeable future." In the past, whenever the FOMC had issued such a statement at one meeting, it had cut its funds rate target at (or before) the next scheduled meeting. Many analysts had begun to interpret this statement-that risks are weighted mainly toward conditions that may generate economic weakness-as almost a guarantee of a target cut at the next FOMC meeting.

The table summarizes how FOMC statements about risks issued at one meeting have been followed by federal funds rate target actions at or before subsequent scheduled meetings since February 2000. On 11 of 13 occasions when the FOMC issued a statement that risks were weighted mainly toward conditions that may generate economic weakness ("Weakness"), the FOMC cut its funds rate target at or before the subsequent scheduled meeting by either 25 or 50 basis points. Three of these cuts were made between scheduled meetings, and on each of these three occasions the FOMC issued a new statement to the effect that risks were weighted mainly toward economic weakness.

By contrast, the FOMC changed its funds rate target at only two of seven meetings following a meeting at which the Committee had concluded that risks were weighted mainly toward conditions that may generate heightened inflation pressures ("Inflation"). Clearly, an FOMC statement that risks are weighted more toward economic weakness or toward inflation pressures has been no guarantee of a target change at or before the next meeting. Nevertheless, when the FOMC has changed its target, the change always has been in the direction one might forecast on the basis of the risks statement issued at the previous meeting. For example, the target has never been cut when the statement issued at the previous meeting indicated that risks are weighted toward conditions that may generate heightened inflation pressures.

In addition to indicating the Committee's views about economic risks over the foreseeable future, the statement issued at the conclusion of the March 19, 2002, FOMC meeting for the first time also reported the roll call vote on the funds rate target taken at the meeting. As with the risks statement, the decision to announce the vote on the target at each meeting is sure to attract close scrutiny from those hoping to divine the Committee's next moves. It remains to be seen whether such information adds to the predictability of target changes.

\section{Balance of Risk Statements and Subsequent Target Actions Since February 2000}

\begin{tabular}{lccc}
$\begin{array}{l}\text { Risk statement } \\
\text { at previous meeting }\end{array}$ & $\begin{array}{c}\text { Target } \\
\text { cut }\end{array}$ & $\begin{array}{c}\text { No change } \\
\text { in target }\end{array}$ & $\begin{array}{c}\text { Target } \\
\text { increase }\end{array}$ \\
\hline Weakness & 11 & 2 & 0 \\
Inflation & 0 & 5 & 2
\end{tabular}

